\title{
Antirracismo no currículo da EDUCAFRO: um movimento negro em direção à universidade
}

\author{
Sara C. de Castilho Dâmaso dos Santos ${ }^{1}$
}

Amilcar Araújo Pereira²

\section{Resumo}

O objetivo deste artigo é refletir sobre a atuação de pré-vestibulares populares, a partir do exemplo da EDUCAFRO, no enfrentamento das desigualdades sociais e do racismo que as estrutura. Lutas por ações afirmativas e ingresso de pobres, negros e negras aparecem na organização como estratégia de transformação de vidas e da sociedade como um todo, sobretudo no campo das relações étnico-raciais. Essa transformação passa pela ocupação de espaços historicamente negados à população negra e pela formação de subjetividades a partir de um currículo que abarca saberes antirracistas produzidos e sistematizados pelo movimento negro.

\section{Palavras-chave}

Movimento negro; antirracismo; Educafro; Pré-Vestibular.

Anti-racism in the EDUCAFRO curriculum: a black movement towards the university

\begin{abstract}
The aim of this article is to reflect on the performance of pré-vestibulares populares (courses created to prepare poor people to the national exam which is used to select students to the universities in Brazil), based on the example of EDUCAFRO, in the confrontation of social inequalities and the racism which structures them. Struggles for affirmative action and entry of the poor and blacks at the universities appear in the organization as a strategy for transforming lives and society as a whole, especially in the field of ethnic-racial relations. This transformation involves the occupation of spaces historically denied to the black population and the formation of subjectivities based on a curriculum that includes anti-racist knowledge produced and systematized by the black movement.
\end{abstract}

\section{Keywords}

Black movement; anti-racism; Educafro; Pré-Vestibular. 
Negro, não se humilhe nem humilhe a ninguém

Todas as raças já foram escravas também

E deixa de ser rei só na folia e faça da sua Maria uma rainha todos os dias

E cante o samba na universidade

E verás que seu filho será príncipe de verdade

Candeia (Dia de graça, 1970)

\section{Introdução}

Educação e cidadania para afrodescendentes e carentes. Com termos diferentes de acordo com o contexto histórico - instrução, liberdade, educação, cidadania - essas são bandeiras antigas de negros e negras em luta no Brasil. Desde o período escravista a população negra luta por educação. Durante o Período Republicano o acesso à educação foi sendo ampliado através de políticas de universalização. O último desses avanços foi a ampliação da obrigatoriedade do ensino para a Educação Básica (4 a 17 anos) - Da pré-escola ao ensino médio33.

O Ensino Superior público e gratuito continua tendo acesso restrito, através de avaliação meritocrática, ainda excluindo pobres, negros, indígenas e outras minorias, que, apesar de já terem o acesso à educação básica até os dezessete anos garantido por lei, têm suas trajetórias atravessadas por situações como precarização da escola pública, inserção precoce no mundo do trabalho e acesso restrito a serviços e equipamentos culturais. Como já dizia o grande sambista e militante negro Candeia, no samba Dia de graça, composto por ele ainda em 1970, o acesso da população negra à universidade, tem sido um objetivo e um objeto de muita luta protagonizada pelo movimento negro na história do Brasil. A partir dessa realidade, na Década de $1990^{4}$ difundiram-se no país pré-vestibulares populares.

A multiplicação de Cursos Pré-Vestibulares Populares pelo Brasil a partir de meados da década de 1990 e na década de 2000 demonstra a explosão de uma nova demanda, que até o início dos anos de 1990 era pouco expressiva: a demanda dos pobres e marginalizados por acesso ao ensino superior. (NASCIMENTO, 2010, p.47) 
Este artigo foi construído a partir de reflexões desenvolvidas em pesquisa de mestrado ${ }^{5}$ que buscou aproximar-se de uma organização do movimento negro que luta por essas demandas e teve participação em mudanças no espaço universitário com a ampliação da presença de negros e negras. Um curso pré-vestibular popular que se configura como movimento negro.

Entende-se como Movimento Negro as mais diversas formas de organização e articulação das negras e dos negros politicamente posicionados na luta contra o racismo e que visam a superação desse perverso fenômeno na sociedade. Participam dessa definição os grupos políticos, acadêmicos, culturais, religiosos e artísticos com o objetivo explícito de superação do racismo e da discriminação racial, de valorização e afırmação da história e da cultura negras no Brasil, de rompimento das barreiras racistas impostas aos negros e às negras na ocupação dos diferentes espaços e lugares na sociedade. (COMES, 2017, p.23)

A Educação e Cidadania de Afrodescendentes e Carentes (EDUCAFRO $)^{6}$ surge como pré-vestibular na década de 1990, fundada por um grupo que conjuga militantes negros e franciscanos.

Neste artigo objetivamos apresentar a EDUCAFRO como pré-vestibular popular com agência antirracista em torno das ações afırmativas, tanto no campo do acesso ao Ensino Superior, quanto no campo da construção de currículo, ambos fundamentais para a transformação social. Nosso recorte de análise aborda a EDUCAFRO de forma ampliada, mas coloca seu enfoque sobre a EDUCAFRO Rio ${ }^{7}$, mais especificamente, sobre o núcleo pré-vestibular FGV-Nelson Mandela, localizado no Centro da capital. Fazemos esse recorte em três perspectivas, pois há estruturas que organizam a EDUCAFRO de forma geral, assim como há especificidades locais. No desenvolvimento da pesquisa que deu origem a esse trabalho foram desenvolvidas metodologias de análise documental, observação participante e história oral, a partir de entrevistas produzidas com voluntários da 
EDUCAFRO no contexto da pesquisa e de entrevista produzida em 2004 com o fundador e principal porta voz da organização, Frei David Raimundo dos Santos ${ }^{8}$.

\section{Apresentação da EDUCAFRO}

A EDUCAFRO está presente em diferentes estados brasileiros, através de núcleos pré-vestibulares, e reúne representantes de diferentes âmbitos da sociedade. Fundada por um membro da ordem Franciscana, sua história remonta a outra organização, da qual seus fundadores desvincularam-se, o Pré-vestibular para negros e carentes (PVNC). Esse teve sua fundação em 1993 e, em 1997, a EDUCAFRO foi fundada por um grupo dissidente do PVNC, incluindo Frei David Santos, que esteve envolvido com grande destaque na construção do PVNC. A partir de 1998 as duas organizações passaram a atuar de forma independente, e ambas "são referências no Movimento dos Cursos Pré-Vestibulares Populares e as organizações mais conhecidas pela sociedade em geral. Em diversos momentos, essas organizações assumem o papel de representantes dos cursos pré-vestibulares populares." (NASCIMENTO, 2010, p.105). Frei David Santos nos conta sobre a fundação do PVNC:

O pré-vestibular nasceu a partir de uma reunião que fizemos lá em São João de Meriti, na paróquia dos franciscanos, com a juventude franciscana da paróquia. (...) em todo grupo de que eu participava, eu levantava a questão do negro na universidade. E a gente foi e fez nascer em 89... Tivemos uma reunião em São Paulo, em 89, com um grupo de negros católicos, e um dos temas centrais foi isso aí: a exclusão do negro da universidade. Existia lá em São Paulo o padre Batista, um padre negro muito guerreiro, e aí marcou-se uma reunião com o cardeal dom Paulo Evaristo Arns $^{9}$. Objetivo: propor ao cardeal que ele, que era o chanceler da PUC em São Paulo, determinasse (...) um número de bolsas, para negros do Brasil inteiro que estivessem trabalhando e lutan- 
do em prol da consciência negra. (...) O reitor, de maneira muito violenta, muito racista, disse não, porque aquilo era racismo. (...) Este fato me fez buscar estratégias. (...) no Rio de Janeiro, vamos tentar fazer nascer um pré-vestibular para ajudar o povo a entrar nas faculdades públicas e vamos tentar convencer pessoas para ajudar a gente cedendo bolsas em universidades particulares, como a PUC-Rio, mas em hora nenhuma usar o nome negro, vamos falar carente (...) Já o pré-vestibular, vamos radicalizar: vamos fazer Pré-Vestibular para Negros. (...)

A proposta era: só professores negros e só para alunos negros.

(...) não existiam negros na nossa região preparados em universidades para serem professores no pré-vestibular. (...) E isso nos levou a um trauma, a grandes discussões, e aí então em 92 decidimos abrir, aceitar qualquer um que quisesse ser professor. E iríamos ter só alunos negros.

(...) começaram a aparecer alguns professores brancos e negros para ajudar, e montamos em 93 a primeira turma. (...) o título era "Pré-Vestibular para Negros", mas tinha mais ou menos, vamos botar aí uns 30\% de brancos entre alunos. A gente radicalizou no nome, mas deixou mais light na composição.

E aí estourou uma revolução dentro desse pré-vestibular: professores e alunos brancos e negros não conscientes falaram: "Ou vocês tiram o nome negro ou nós professores vamos embora daqui." Foi um vai e vem, reuniões e mais reuniões, faz não faz, e com muita estratégia conseguimos convencê-los a não tirar o nome negro, mas botar um outro nome, incluir o nome carente. Aí ficou (...) "Pré-Vestibular para Negros e Carentes”. O trabalho foi adiante, a palavra carente amorteceu os conflitos e a própria sociedade começou a acolher mais a idéia, a imprensa começou a acolher mais a ideia. (...) o trabalho pegou pique e nesse ínterim conseguimos um acordo com a PUC-Rio para bolsas para pobres ${ }^{10}$.

Nesta narrativa é possível perceber diferenças entre os envolvidos e a importância das negociações na construção do PVNC. Bhabha (1998) aponta a diferença como possibilidade de construção de novos 
espaços de significação subalterna. Nesse sentido, Frei David e Padre Batista aparecem construindo novas possibilidades a partir de seu posicionamento dentro da Igreja, mas para isso, precisaram negociar com figuras de poder com visões diferentes das suas. Além disso, na construção do curso, não foi possível a homogeneidade a princípio desejada, no sentido da construção de uma radicalidade na perspectiva da raça. Assim, sujeitos com diferentes pertencimentos raciais encontraram-se no curso, e, essas diferenças fizeram emergir novas negociações, buscaram ser representadas, influindo na alteração do nome do curso, que passa a incluir a palavra carente. Essa negociação interna pareceu dialogar com a sociedade, produzindo maior aceitação e diminuição de barreiras, o que faz sentido em uma sociedade que, em certa medida, nega a existência do racismo e ainda vê, em muitos casos, as lutas antirracistas e as políticas de ações afırmativas como provocadoras de racismo"1.

Outras tensões e negociações no PVNC culminaram com a fundação da EDUCAFRO ${ }^{12}$, que se tornou uma rede de pré-vestibulares comunitários com ação ampliada, mediando relações com universidades privadas na busca por bolsas de estudos e envolvida em lutas políticas pelas ações afırmativas. Atualmente é estruturada a partir de uma sede, em São Paulo, e se espalha por diferentes estados e municípios. Ela tem uma organização burocrática que permite a coordenação do trabalho em níveis ampliados, mas há certa autonomia no trabalho desenvolvido nos núcleos pré-vestibulares.

\section{Agência da EDUCAFRO na construção de ações afirmativas}

Nas lutas pelas políticas de ação afırmativa como forma de combate às desigualdades e democratização de direitos, pré-vestibulares populares ampliaram as bases sociais do movimento negro (NASClMENTO, 2010) e diferentes trabalhos (NASCIMENTO, 2010; SIQUEIRA, 2011; SCHWARTZMAN, 2009) destacam que na construção e manutenção das políticas de ações afırmativas em Universidades públicas 
a EDUCAFRO teve atuação relevante. Ela atuou nas lutas pela implementação das políticas de ações afırmativas na Universidade do Estado do Rio de Janeiro (UERJ), primeira universidade brasileira a implementar cotas raciais, e nas universidades públicas em nível nacional. Essa atuação em favor das cotas continua atualmente. Em 2018, no contexto da reavaliação da política pela UERJ na Assembleia Legislativa do Rio de Janeiro (ALERJ) a EDUCAFRO esteve presente.

A organização busca também construir o acesso às cotas pelos estudantes negros, que, por vezes não se apropriam desse direito ao acionarem discursos que entendem as cotas como um tipo de racismo que os desqualifica. Schwartzman (2009) destaca, em sua pesquisa, que a EDUCAFRO e o PVNC foram as organizações que mais influenciaram os estudantes que entrevistou na UERJ a acionarem o direito às cotas.

Além da luta pelas cotas raciais a agência antirracista da EDUCAFRO se estabelece no que tange às ações afirmativas no currículo. Nas salas de aula e em diferentes espaços formativos da organização estudantes e voluntários (professores ${ }^{13}$ ou em outros cargos) têm contato com saberes que valorizam lutas em torno da construção identitária da negritude e uma cidadania combativa pelas ações afırmativas e contra o racismo. Saberes produzidos e sistematizados pelo movimento negro, "transformados em reivindicações, das quais várias se tornaram políticas de Estado nas primeiras décadas do século XXI" (GOMES, 2017, p.14).

\section{Professores e estudantes em educação antirracista}

Os voluntários à frente da coordenação da EDUCAFRO Rio ${ }^{14}$ buscam professores comprometidos com as lutas da organização. voluntário L, afirma que todos os professores são aceitos, mas nem todos permanecem:

O pessoal da EDUCAFRO mesmo, que já tem um tempo, a gente procura dar essa parte de cultura africana, procura dar uma ênfase nisso também, dar um reforço nisso. Mas tem professores de todo tipo. (...) conheci professores que são contra as 
cotas (...) o cara já é branco e vai contra as cotas, aí acaba com o aluno. O aluno já é todo massacrado, aí o cara chega na sala de aula e destrói mais ainda, não tem condição. (...) Não tem como deixar um professor que não seja a favor das cotas, que não seja a favor das religiões de matriz africana, não tem sentido. A gente vai trabalhando. $\mathrm{O}$ que a gente tem no momento a gente usa, às vezes não faz muito sentido, mas a gente tem que usar para não deixar um buraco ${ }^{15}$.

Como uma organização que funciona através de voluntariado, a EDUCAFRO precisa aceitar professores com posicionamentos conflitantes com suas lutas. Entretanto, quando possível, eles são substituídos por outros professores, por vezes desestimulados de atuar em uma organização que luta por ideais nos quais não acreditam. Entretanto, enquanto atuam em salas de aula da EDUCAFRO suas identidades, pertencimentos e saberes estarão presentes no currículo. Isso nos faz refletir sobre como no espaço-tempo de fronteira do currículo, culturas se legitimam de forma diferenciada (MACEDO, 2006). Assim, as tendências homogeneizadoras se fazem presentes no currículo da EDUCAFRO a partir do ENEM, e dos saberes valorizados pela organização, mas elas não apagam a diferença.

para além dos discursos homogeneizantes - do lluminismo, do mercado, da nação -, o currículo escolar é habitado por uma diferença que não se define como a oposição ao homogêneo, que penso ser possível tratá-lo como uma espécie de espaço-tempo cultural liminar. Um espaço-tempo em que as culturas presentes negociam com “a diferença do outro", que explicita a insuficiência de todo e qualquer sistema de significação. (MACEDO, 2006, p.292)

Somos seres em construção, já que "Estamos sempre em processo de formação cultural." (HALL, 2003, p.44) Assim, o contato com a EDUCAFRO, organização do movimento negro que reeduca a sociedade para as relações sociais (COMES, 2017) pode afetar as subjetivi- 
dades desses professores. Isso foi o que aconteceu com o voluntário J., que nos mostra como sua presença na EDUCAFRO foi importante para uma mudança na sua visão sobre a questão racial no Brasil:

Eu demorei anos para entender a importância da cota, a importância da não redução [da maioridade] penal. Porque com a redução penal a maioria que vai ser afetada, todo mundo sabe quem vai ser, vai ser a parcela negra, o branco vai conseguir um bom advogado e sair ${ }^{16}$.

Entendemos que professores e demais voluntários, assim como os alunos, estão em formação na EDUCAFRO. Como ex-alunos ou pelo contato com os saberes do movimento negro na organização, os voluntários são afetados pelo currículo. Desta forma, apesar de não haver prescrição para o trabalho nas salas de aula com questões raciais e com histórias e culturas da África e dos afro-brasileiros além das cobranças do ENEM e vestibulares, essas temáticas são incorporadas com bastante força. São temáticas caras às trajetórias de muitos professores, e, nos casos em que essas reflexões ainda não haviam sido desenvolvidas, costumam emergir para os docentes que permanecem na organização, afetados por um currículo cujas fronteiras abarcam relações com outros voluntários e com os alunos que participam dos diferentes espaços formativos da EDUCAFRO. Ao serem afetados por esse currículo antirracista, os professores passam a trazer tais questões como parte de seus saberes, identidades e pertencimentos, reconstruídos a partir do que Bhabha (1998) chamou novos signos de identificação, o que fará com que estejam presentes nas fronteiras que se desenham nos currículos de suas aulas.

De acordo com Lima (2018) o contato com o movimento negro organizado tem o potencial de afetar professores, colocando-os em contato com uma "cultura de luta antirracista".

Para o autor [Amílcar Cabral], a luta pela libertação cria uma cultura que afeta, que contagia os indivíduos através do contato, 
dessa maneira, tais indivíduos estariam mais ou menos propensos a engajar-se na luta pela libertação considerando o quanto estivessem em contato com o que estamos chamando aqui de "cultura de luta". A partir do apoio teórico de Hall, e Bhabha estabelecemos que essa cultura de luta pode ser produzida em outros espaços de luta por direitos, como por exemplo, o movimento negro, grande protagonista na luta antirracista no Brasil. Assim como o contato com a cultura de luta promove transformações nos indivíduos em relação a luta pela independência, o contato com a cultura de luta antirracista afeta os indivíduos, nos interessando aqui de maneira específica os docentes, e promove transformações em relação às práticas que se estabelecem em suas salas de aula, de maneira a produzir transformação cultural ou ao menos a instabilidade que lhe dá corpo. (LIMA, 2018, p.97)

O contato com essa cultura de luta pode se estabelecer também, segundo a autora, através de cursos de formação inicial e continuada e na comunidade escolar, em processo de formação continuada dos professores. Na EDUCAFRO os professores têm esse espaço de formação continuada através do contato com a organização enquanto movimento negro, além de muitos serem ex-alunos, o que os faz ter contato com essa cultura de luta antes mesmo do ingresso no Ensino Superior.

Alguns professores já ingressam na organização buscando construir oportunidades para o povo negro e pobre, com uma análise racial da sociedade que os aproxima da organização, outros passaram a compreender a questão racial a partir de seu contato com a EDUCAFRO. O engajamento que orienta as aulas dos professores "mais antigos" traz para a sala de aula saberes presentes no que chamamos currículo formal da EDUCAFRO. Ele não chega aos professores sob a forma de uma prescrição, mas pela formação continuada em contato com a cultura de luta antirracista da EDUCAFRO, que afeta suas subjetividades.

As identidades e pertencimentos de professores que buscam atuar na EDUCAFRO por suas lutas se evidenciam nos currículos de suas aulas. O professor $A$. relata as oportunidades que teve, mesmo em 
uma situação social desprivilegiada e nos conta como decidiu apoiar estudantes pobres a entrarem na Universidade:

Sou aquele famoso primeiro da família a entrar na Universidade. Passei boa parte da minha vida na Ladeira dos Tabajaras, em Copacabana. Ninguém da minha família tinha mais do que a quarta série, em média. (...) o Pedro II, o colégio em que eu estudei o nível médio e parte do Ensino Fundamental, estava passando por uma reestruturação e eles pegaram todos os alunos da escola pública, sem concurso, que tinham conceitos $\mathrm{A} e$ B, e eu fui para o Pedro II em 1980, e foi a virada da minha vida. (....) Até que eu cheguei a um momento da profissão em que eu estava estável. Eu estou num momento estável, e comecei a olhar pra trás. (...) eu cheguei aqui e senti que eu tenho um compromisso. Que eu estudei a minha vida toda em escola pública. A única instituição privada em que eu estudei foi a PUC. Com dinheiro público. E que outras pessoas chegassem aqui. Porque eu cheguei e outras pessoas não.

(...) Eu estou aqui na universidade, dou aula aqui na UFRJ há muito tempo. Dei aula na PUC, também, quando eu fazia doutorado e era professor. E tinha um aluno, o perfil de um aluno classe média alta. (...) muitos alunos estavam lá porque era muito fácil pra eles estar, mas eles não queriam estar lá, eles falavam isso. O pai obrigava. "Eu estou aqui porque o meu pai me obriga. Eu não quero estar aqui." E, por outro lado, você tem, na EDUCAFRO, o cara que daria um braço para estar lá, mas não tem oportunidade ${ }^{17}$.

A professora G. relata sua percepção do racismo como estruturante das desigualdades, marcadas em sua trajetória, e, como essa percepção contribuiu para que buscasse lutar contra o racismo através da educação, atuando na EDUCAFRO. A proximidade da história de vida de professores com a realidade dos alunos possibilita que sejam referências para eles, exemplos de trajetórias transformadas através da educação e de posturas de luta frente às dificuldades. A professora identifica a importância desse tipo de referência na vida dos estudantes a partir do olhar sobre a própria trajetória: 
Eu gostaria muito que a gente tivesse estudado mais, que meus irmãos tivessem estudado. Eu gostaria muito que eu tivesse estudado mais, que a minha escola não ficasse tanto tempo em greve. Eu gostaria muito que na rua tivesse uma mulher que fosse advogada, que fosse negra e que ela dissesse: "vão estudar!". Eu gostaria muito de ter tido isso. Eu acho que a minha vida teria sido um pouquinho melhor. Porque eu cresci sem referência. (...) Meu tio não serviu o quartel, porque era arrimo de família, minha mãe fez até o “admissão", não sabe ler nem escrever muito bem. Eu não tinha referência, eu não tinha alguém que eu pudesse dizer que eu queria ser igual, ou que me dissesse de uma forma mínima o caminho melhor pra eu seguir. Eu tive que fazer tudo isso sozinha. E esse processo não é bacana sozinha. Então, eu acho que eles se identificam demais, porque eu explico sempre, pra todas as turmas que chegam, qual é a razão de eu estar lá e o que é que a gente vai fazer dali por diante ${ }^{18}$.

A percepção da dimensão do racismo demonstrada por essa professora não fica fora de suas aulas de redação:

Eu vou estar sendo hipócrita se eu disser pra você que a questão do racismo e do preconceito não estão sempre presentes. Isso é uma coisa recorrente. Por outro lado, eu procuro trazer os temas das universidades, o que caiu na UERJ, na PUC, na FGV e no ENEM. Esse é o meu mote principal. Então eu tenho, sei lá, 35\% falando sobre preconceito e discriminação, de todos os gêneros, e, todo o resto é o que caiu nos vestibulares ${ }^{19}$.

Em certa medida o ENEM tem fortalecido o trabalho desenvolvido pela professora, pois tem apresentado conteúdos relativos à Lei 10.639/0320, inclusive em temas de redação²1 (SANTOS, 2019).

Eu acho que tem aparecido bem. No ENEM, então, quando ele falou sobre discriminação religiosa, não foi? Foi ótimo, acho que tem aparecido bem. (...) É um tema recorrente [nas minhas aulas] tenho certeza que quem estudou comigo não teve problemas ${ }^{22}$. 
Já em relação às disciplinas ligadas às ciências exatas, a recorrência de conteúdos ligados à Lei 10.639/03 no ENEM é muito baixa (SANTOS, 2019). Assim, a negociação entre o currículo do ENEM e os saberes antirracistas da EDUCAFRO parece mais complexa.

Quando eu estava no Nelson Mandela, praticamente não tinha, quase não foi abordado isso [a questão racial], mas eu lembro que na minha primeira experiência, no pré, há muito tempo atrás, na PUC, eu levava muito isso, muito. (...) nas minhas aulas eu falava bastante. E dava uma formação. Passava minha visão dessas diferenças, dessas desigualdades, dessas injustiças. No Nelson Mandela poucas vezes teve oportunidade de falar isso, porque o tempo era bem mais reduzido. Eu praticamente não abordava nas aulas, mas eu abordava nas reuniões da EDUCAFRO ${ }^{23}$.

O relato do professor nos indica que ele não deixava de trabalhar a questão racial nas aulas por lhes conferir pouca importância, tendo em vista que em outro curso era um tema recorrente em suas aulas. Ele nos aponta a escassez de tempo na aula e o uso de outros espaços disponibilizados pela EDUCAFRO para o desenvolvimento de tal debate. Espaços em que o professor sabe que a questão racial será privilegiada e que, em geral, não estão presentes em outros cursos. $O$ professor A. não apenas direciona o debate racial e social para outros espaços da EDUCAFRO, mas também se faz presente neles, atuando e pensando sua construção e as questões a serem trazidas. Ele demonstra em sua entrevista que o ingresso na universidade é importante, mas é só uma parte do processo, a transformação das subjetividades, "mexer com a cabeça", é tão importante quanto a possibilidade de ingressar no Ensino Superior e ascender socialmente.

ele [aluno] chega lá sem nenhuma visão sobre essas questões raciais. Para muitos é o primeiro contato que têm, então a gente tem essa preocupação de mostrar pra eles. A gente tenta fazer trabalhos de formação de questões sociais, mas também mexer com a cabeça do cara, porque o cara chega quebrado, quebrado 
mesmo. É aquele povo colonizado, que você quebra psicologicamente. A questão da autoestima. Isso são questões difíceis de trabalhar. Eu nunca consegui fazer isso nas aulas ainda. Mas, nas nossas reuniões a gente tenta fazer isso. $(. . .)^{24}$.

Esse professor é visto frequentemente nas Reuniões Gerais onde conta sua vivência como professor de física negro na universidade pública e convida os estudantes a ocuparem esse espaço. Essa presença pode refletir nas salas de aula uma perspectiva do professor como referência, o que impacta no currículo, tendo em vista que as identidades e pertencimentos dos professores e estudantes são formativas do currículo e estão em negociação, podendo dar origem a novos signos de identidade (BHABHA, 1998).

Entendendo essa formação de identidades em negociação, não buscamos afirmar aqui que o currículo construído na EDUCAFRO irá afetar a todos os estudantes e alunos de modo a que desenvolvam uma postura antirracista, pois

nem as narrativas tradicionais da escola, nem os projetos críticos de formação de um cidadão emancipado, nem a hegemonia eurocêntrica ampliada, nem a colonização da escola pela ciência são capazes de impedir o surgimento de temporalidades disjuntivas (MACEDO, 2006, p.289).

Não é possível prever os impactos que o contato com o currículo trará para as subjetividades dos envolvidos. Ele tem efeitos inesperados, pois o contato entre os diferentes produz novos signos, para todos os envolvidos, e não são uma via de mão única. Enquanto espaço-tempo de fronteira, híbridos culturais, os currículos constituem práticas ambivalentes que "incluem o mesmo e o outro num jogo em que nem a vitória nem a derrota jamais serão completas" ((MACEDO, 2006, p.289). O que afırmamos é que esse currículo tem potencial de educação antirracista, pois coloca em suas fronteiras saberes, identidades e pertencimentos construídos e sistematizados pelo movimento 
negro como reeducadores da sociedade. E esses saberes, identidades e pertencimentos irão afetar, de alguma forma, os sujeitos, dando lugar a formação de "entrelugares" 25 na construção de suas identidades, sempre múltiplas e em permanente transformação, "produzidas parcialmente, de modo discursivo e dialógico" (HALL, 1997: 27).

\section{Diferentes espaços de construção do currículo na EDUCAFRO}

Na EDUCAFRO a formação não acontece apenas nas salas de aula. A organização desenvolve espaços onde traz para as fronteiras do currículo saberes que considera importantes, sem precisar negociar com provas de seleção. Entre esses espaços citamos alguns, através dos quais é possível perceber como o currículo da EDUCAFRO comporta saberes que podem despertar, no estudante, a identificação como negro e participação nas lutas pelos direitos dos negros. Mais que isso, enquanto movimento negro, a EDUCAFRO constrói saberes em suas lutas, dos quais fazem parte voluntários e estudantes.

Conforme mencionamos, a EDUCAFRO não restringe seu atendimento a negros e negras. Segundo o coordenador da EDUCAFRO-Rio,

o branco pobre, ele vai estudar no mesmo local que você, na mesma coisa que você, só que a inserção e o crescimento dele profissional vão ser mais rápidos que você, porque ele não teve as amarras no passado, não tem família que foi escrava, não tem isso que nem negro, não sofre a questão cultural racial que o nosso Brasil tem. Então a EDUCAFRO pensa o seguinte: (...) o pré-vestibular comunitário reúne todo mundo que está à margem da sociedade, não só negro. Nordestino, a mulher (...) o de matriz africana, ecumênico, todo mundo, todo mundo, entendeu? Não adianta você focar só num grupo onde você não consegue atender todo mundo. (...) inserção do branco pobre, que também precisava ser amparado ${ }^{26}$.

Além de oferecer uma oportunidade de ingresso no Ensino Superior a esses sujeitos não negros, a EDUCAFRO os coloca em contato com 
uma educação antirracista, o que é uma contribuição para a reeducação de toda a sociedade para as relações étnico-raciais. Sujeitos brancos e de outros pertencimentos raciais são colocados, em múltiplos espaços da EDUCAFRO, em contato com debates que evidenciam o caráter racial das desigualdades sociais e a necessidade de ações afırmativas para a correção dessas desigualdades.

Elencamos como primeiro desses espaços a porta de entrada para a EDUCAFRO, para acesso a bolsas de estudo ou ao curso pré-vestibular, a Prova de Cidadania. Ela se baseia nos Temas de Cidadania, textos que trazem saberes construídos pelo movimento negro, inclusive pela EDUCAFRO. Entre os temas encontramos: a marginalização do negro no Brasil; a experiência urbana dos jovens negros; violência policial; desafios da militância negra frente à violência de gênero; defesa dos direitos humanos por afro-brasileiros; universidades públicas; ações afirmativas; e, políticas públicas para negros na universidade.

Ao ingressar na EDUCAFRO o estudante é recebido em uma Reunião de acolhida. Nela, voluntários apresentam a organização, suas lutas e saberes. No depoimento de um professor e ex-aluno temos a percepção da importância desse espaço na formação de subjetividades dos estudantes:

a primeira coisa que ele [o voluntario] começou a me falar foi sobre "situação do negro no Brasil", pra todo mundo, começou a falar de política, de conjuntura econômica, social, os fatores psicológicos, de racismo. E eu, que fui só pra conseguir uma bolsa, começava ali a minha formação política. E aí, eu nunca mais saí da EDUCAFRO (...) porque ali eu comecei a ver que eu tinha outros referenciais de negro (...) ali eu começo a me reconhecer como negro ${ }^{27}$.

A EDUCAFRO promove mensalmente a Reunião Geral ${ }^{28}$, onde se fazem presentes temáticas como Identidade negra, cotas raciais, desigualdades sociais, racismo, educação e possibilidades de mudança. 
Temáticas que se evidenciam como saberes identitários, políticos, e estético corpóreos, que, de acordo com Comes (2017), são produzidos e sistematizados pelo movimento negro. Nessas reuniões são apresentados Informes sobre oportunidades nas áreas de estudo, trabalho e acesso a direitos. São ainda apresentadas e valorizadas lutas e conquistas políticas da EDUCAFRO e de outras organizações do movimento negro. Além de apresentar essas lutas, a reunião torna-se um espaço para sua organização, onde se articulam militantes para atuar em atos a serem desenvolvidos pela EDUCAFRO.

Essa militância configura-se também como espaço formativo onde encontram-se profissionais reconhecidos em suas áreas de atuação, estudantes almejando uma graduação ou profissionais em formação. Pessoas atuantes no movimento negro há décadas com outras, começando seu caminho nessa forma de luta. O encontro de pessoas nessas diferentes condições é um espaço formativo, com ricas possibilidades para os envolvidos. Nessa militância saberes do movimento negro são formadores dos estudantes e voluntários da EDUCAFRO e, ao mesmo tempo, formados por eles, em diálogo com suas identidades e trajetórias.

No sentido de garantir nos núcleos pré-vestibulares a presença de conteúdos não necessariamente cobrados para o ingresso no Ensino Superior existe a disciplina cultura e cidadania. Espaço proposto desde o PVNC,

a aula de cultura e cidadania passa a ser o espaço que dá o rumo para o projeto e que qualifica o aluno para além do pré-vestibular. O projeto passou a ser um instrumento poderosíssimo de discutir e aprofundar a questão racial, a questão da autoestima, a questão das ações afırmativas ${ }^{29}$.

A disciplina visa aprofundar o debate sobre cultura, cidadania e tudo o que tangencia esses temas. Assim, emergem questões como direitos, política e diferença, por exemplo. 


\section{Considerações finais}

Mais do que um espaço para acesso ao Ensino Superior, a EDUCAFRO, como pré-vestibular popular e organização do movimento negro é uma ferramenta de agência para a transformação social. Desde sua fundação atua na luta pelo acesso ao Ensino Superior para negros e pobres através de parcerias com universidades privadas e da luta politica por ações afırmativas em universidades públicas. Para além de transformar a vida dos indivíduos beneficiados pelo ingresso no Ensino Superior, a agência da EDUCAFRO contribui para a transformação do espaço acadêmico, pois, junto a outros pré-vestibulares populares, potencializa o ingresso de sujeitos historicamente excluídos desse espaço.

Essas são questões que atravessam o currículo construído na EDUCAFRO, enquanto espaço-tempo de fronteira onde as diferenças são negociadas e as subjetividades são afetadas (MACEDO, 2006). A transformação do espaço acadêmico - e da própria sociedade de forma mais ampla - é notadamente articulada a mudanças nas subjetividades de pessoas e grupos. Sujeitos que, percebendo os mecanismos de exclusão nos quais estão engendrados, e ocupando posições historicamente negadas a indivíduos com seu pertencimento racial e social, podem ser capazes de promover "instabilidade produtiva de mudança cultural".

os jovens estudantes universitários de origem popular que vêm ingressando nos anos recentes na universidade pública brasileira, negros em grande parte, podem ser vistos, como diriam Fanon e Bhabha, como parte do "grupo liberatório" que pode contribuir para a "instabilidade produtiva da mudança cultural", tanto na universidade quanto em nossa sociedade (PEREIRA, 2015, p.77).

Pereira afırma que esse processo produz identidades híbridas, no dizer de Bhabha (1998). Estes estudantes trazem seus pertencimentos étnico-raciais para a produção e o compartilhamento de conhecimento, “buscando escapar ao eurocentrismo e ao 'elitismo' predominantes na universidade desde o início de sua formação acadêmica, 
sem deixar de aprender com o que a universidade pode lhes oferecer em termos de crescimento" (PEREIRA, 2015, p.78). Eles transformam a universidade enquanto são transformados por ela. Do mesmo modo, entendemos que os estudantes que passam pela EDUCAFRO transformam-se e transformam-na nessa passagem. Ingressando na Universidade após passarem pela EDUCAFRO, levarão para esse novo espaço as perspectivas construídas em diálogo com a organização.

Nesse sentido o currículo antirracista da EDUCAFRO contribui para a transformação da universidade, tendo em vista que seus estudantes já travaram contato com saberes emancipatórios construídos e sistematizados pelo movimento negro (COMES, 2017) e os levam às instituições de Ensino Superior. Além de levarem suas experiências e questões, marcadas pela vivência do racismo na sociedade brasileira e também pelo antirracismo no currículo da EDUCAFRO, muitos jovens negros fazem hoje o que Candeia indicava no samba que serviu de epígrafe para este artigo, cantam seus sambas na universidade. Além disso, muitos estudantes da EDUCAFRO, ao acessarem o Ensino Superior, têm oportunidades ampliadas de alcançar postos de trabalho e lugares de poder. Desta forma, estabelece-se representatividade nesses espaços e amplia-se a potencialidade de transformação social. Entendemos que há ainda muita "instabilidade produtiva de mudança cultural" a ser feita no Brasil através das lutas de organizações como a EDUCAFRO, que tem potencializado o movimento negro em direção à universidade.

\section{Referências}

ABREU, Martha e MATTOS, Hebe. Em torno das Diretrizes Curriculares para a Educação das Relações Étnico-raciais e para o Ensino de História e Cultura Afro-Brasileira e Africana: uma conversa com historiadores. Estudos Históricos. Rio de Janeiro, 21(41), jan./jun., 2008.

ALMEIDA, Marco Antônio Betine de. e SANCHEZ, Lívia Pizauro. ENEM: Ferramenta de implementação da Lei 10.639/2003 - Competências para a transformação social? Educação em Revista, vol.32 n. ${ }^{\circ} 1$ Belo Horizonte jan./mar. 2016. 
ALBERTI, Verena e PEREIRA, Amilcar Araujo. (orgs.) Histórias do movimento negro no Brasil: Depoimentos ao CPDOC. Rio de Janeiro: Pallas; CPDOC/ FCV, 2007.

BHABHA, Homi K. O local da cultura. Belo Horizonte: Editora da UFMG, 1998. GOMES, Nilma Lino. O Movimento Negro educador: saberes construídos nas lutas por emancipação. Petrópolis, Rj: Vozes, 2017.

HALL, Stuart. "A centralidade da cultura: notas sobre as revoluções culturais do nosso tempo." Educação \& Realidade, Porto Alegre, v. 22, n² 2, p. 15-46, jul./dez. 1997

HALL, Stuart. Da diáspora: identidades e mediações culturais. Belo Horizonte: UFMG, 2003.

LIMA, Thayara Cristine Silva de. A Cultura de luta antirracista e as potencialidades do contato entre docentes de História e o movimento negro para a implementação da Lei 10.639/03. Rio de Janeiro, 2018. Dissertação (mestrado) - Universidade Federal do Rio de Janeiro, Faculdade de Educação, Programa de Pós-Graduação em Educação, 2018

MACEDO, Elizabeth. Currículo como espaço-tempo de fronteira cultural. Revista Brasileira de Educação. V.11, n.32. maio/ago. 2006.

NASCIMENTO, Alexandre do. Do Direito à Universidade à Universalização de Direitos: O Movimento dos Cursos Pré-Vestibulares Populares e as Políticas de Ação Afirmativa. Orientador: Giuseppe Mario Cocco. Tese (doutorado) - UFRJ/ ESS/ Programa de Pós-graduação em Serviço Social. Rio de Janeiro, 2010.

PEREIRA, Amílcar Araújo, O Grupo PET-Conexões de saberes - Diversidade e as construções de identidades na Universidade e nas escolas. In.: COSTA, Warley da; PEREIRA, Amílcar Araújo. (org.) Educação e Diversidade em diferentes contextos. 1 ed. Rio de Janeiro: Pallas, 2015.

SANTOS, Sara Carolina de Castilho Dâmaso dos. Lutas do movimento negro por educação: saberes em fronteira no currículo da EDUCAFRO. Dissertação (mestrado) - Universidade Federal do Rio de Janeiro, Faculdade de Educação, Programa de Pós-Graduação em Educação, 2019.

SCHWARTZMAN, Luisa Farah. Seeing Like Citizens: Unofficial Understandings of Official Racial Categories in a Brazilian University. Journal of Latin American Studies, 41, 221-250. http://journals.cambridge.org Downloaded: 24 Jun 2009 
SIQUEIRA, Camila Zucon Ramos de. Os cursinhos populares: estudo comparado entre MSU e EDUCAFRO - MG. Dissertação apresentada ao Programa de Pós-Graduação em Educação da Universidade Federal de Viçosa. Viçosa, Minas Gerais, 2011.

\section{Notas}

1 Doutoranda em Educação no Programa de Pós-Graduação em Educação da Universidade Federal do Rio de Janeiro (PPCE-UFRJ) e integrante do GEPEAR/UFRJ - Crupo de Estudos e Pesquisas em Educação Antirracista. Mestre em Educação pelo PPCE-UFRJ (2019), especialista em Educação Básica, com ênfase em ensino de História pelo CESPEB-UFRJ (2013) e Graduada em História pela Universidade Federal Fluminense (UFF). É professora na Prefeitura Municipal de Duque de Caxias e técnica em assuntos educacionais no Instituto Federal de Educação, Ciência e Tecnologia do Rio de Janeiro (IFRJ). Número ORCID: https://orcid. org/0000-0003-4503-4768 E-mail: castilhosara27@gmail.com

2 Doutor em História pela Universidade Federal Fluminense (UFF), mestre em ciências sociais pela Universidade do Estado do Rio de Janeiro (UERJ) e gradudo em História pela Universidade Federal do Rio de Janeiro (UFRJ). É professor Associado da Faculdade de Educação da Universidade Federal do Rio de Janeiro (UFRJ). Coordena o GEPEAR/UFRJ - Grupo de Estudos e Pesquisas em Educação Antirracista. Número ORCID: https://orcid.org/0000-0001-7781-6882 E-mail: amilcarpereira@fe.ufrj.br

3 A Emenda Constitucional 59 de 2009 estabelece 2016 como prazo para implementação de suas disposições, o que incluí a obrigatoriedade da Educação Básica.

4 Os cursos pré-vestibulares populares difundiram-se na década de 1990, mas não surgiram nesse momento. Segundo Nascimento (2010) em 1975 foi fundado curso pré-vestibular do Centro de Estudos Brasil-África (CEBA), organização do movimento negro em São Gonçalo, Rio de Janeiro. Ele aponta ainda o surgimento do curso pré-vestibular do projeto "Universidade para Trabalhadores" da Associação dos Trabalhadores em Educação da Universidade Federal do Rio de Janeiro (ASSUFRJ, atual SINTUFRJ).

5 O trabalho foi escrito a partir de reflexões desenvolvidas a partir da pesquisa de mestrado e traz referências à dissertação Lutas do movimento negro por educação: Saberes em fronteira no currículo da EDUCAFRO (SANTOS, 2019), escrita por Sara C. de Castilho D. dos Santos e orientada por Amilcar Araújo Pereira.

6 Registrada sob a identidade jurídica de Francisco de Assis: Educação, Cidadania, Inclusão e Direitos Humanos (FAecidh).

7 Seção da EDUCAFRO no Rio de Janeiro, que conta com uma coordenação local, ligada à coordenação geral da EDUCAFRO. 
8 Entrevista com Frei David Santos, produzida em 2004 no âmbito do projeto "História do movimento negro no Brasil: constituição de acervo de entrevistas de história oral", coordenado por Verena Alberti no CPDOC da Fundação Getulio Vargas. Entrevistadores: Verena Alberti e Amilcar A. Pereira. Trechos da entrevista foram publicados no livro ALBERTI, Verena e PEREIRA, Amilcar Araujo. (orgs.) Histórias do movimento negro no Brasil: Depoimentos ao CPDOC. Rio de Janeiro: Pallas; CPDOC/FCV, 2007.

9 Dom Paulo Evaristo Arns foi arcebispo metropolitano de São Paulo em 1970 e cardeal em 1973. Em maio de 1998 transferiu o cargo de arcebispo de São Paulo para dom Cláudio Hummes.

10 Entrevista com Frei David Santos, já citada.

11 Visão que se pauta no mito da democracia racial. Sobre esta discussão ver PEREIRA, 2013.

12 Sobre a fundação da EDUCAFRO ver SANTOS, 2019 e NASCIMENTO, 2010.

13 Entre os professores da EDUCAFRO há professores de formação e pessoas que lecionam apesar de terem formações em outras áreas, ou estarem ainda em formação. Isso é possível, pois, não há regulamentação para atuação em cursos livres, como um pré-vestibular. A questão da formação certamente tem implicações na sala de aula, entretanto, esse seria um debate necessariamente profundo, que não será possível abordar aqui.

14 Não generalizamos essa afirmativa para a EDUCAFRO de forma geral, pois as fontes de pesquisa que a fundamentam são entrevistas realizadas com voluntários da EDUCAFRO Rio.

15 Entrevista com L., voluntário da coordenação geral da EDUCAFRO Rio, em 05 de abril de 2018, no âmbito do projeto de pesquisa de mestrado que embasou este artigo, no Instituto Ciência Humanas e Filosofia da UFRJ, Centro, Rio de Janeiro.

16 Entrevista com J., coordenador pedagógico do núcleo pré-vestibular FCV-Nelson Mandela, em 05 de abril de 2018,no âmbito do projeto de pesquisa de mestrado que embasou este artigo, na Catedral Presbiteriana do Rio de Janeiro, Centro, Rio de Janeiro.

17 Entrevista com A., professor de física e voluntário da coordenação geral da EDUCAFRO Rio em 06 de setembro de 2018, no âmbito do projeto de pesquisa de mestrado que embasou este artigo, no Instituto de Física da UFRJ, Cidade Universitária, Rio de Janeiro. 
18 Entrevista com G., professora de redação do núcleo pré-vestibular FCV-Nelson Mandela, em 09 de julho de 2018, , no âmbito do projeto de pesquisa de mestrado que embasou este artigo, em escritório de advocacia, Centro, Rio de Janeiro.

19 Idem.

20 Estabelece a obrigatoriedade do ensino de História e Cultura Afro-Brasileira e Africana na Educação Básica. Configura-se como uma forma de ação afirmativa no currículo escolar e é fruto de articulações e lutas políticas do movimento negro (Ver ABREU e MATTOS, 2008).

21 Para mais informações sobre conteúdos referentes à Lei 10.639/03 no ENEM ver SANTOS, 2019 e ALMEIDA e SANCHEZ, 2016.

22 Entrevista com G., professora de redação do núcleo pré-vestibular FCV-Nelson Mandela, já citada.

23 Idem.

24 Ibdem.

25 Bhabha nos fala de um espaço que ultrapassa "as bases de oposição dadas e abre um espaço de tradução: um lugar de hibridismo, para se falar de forma figurada, onde a construção de um objeto político que é novo, nem um e nem outro" (1998, p.51)

26 Entrevista com E., coordenador geral da EDUCAFRO já citada.

27 Entrevista com V., professor de filosofia, sociologia e cultura e cidadania, em 17 de maio de 2018, no âmbito do projeto de pesquisa de mestrado que embasou este artigo, em um café em Santa Tereza, Rio de Janeiro.

28 Durante a pesquisa de mestrado foi realizada observação participante em algumas Reuniões Gerais.

29 Entrevista com Frei David Santos já citada. 


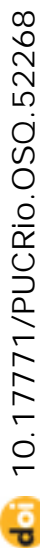

